\title{
The Impact of Implementing External and Internal GSCM Practices on Organizational Performance: Evidence from Manufacturing Firms in Palestine
}

\author{
Ahmed A. Zaid, Abdul Talib Bon, Ayham A. M. Jaaron
}

\begin{abstract}
Provided that green supply chain management (GSCM) practices that integrate ecological thinking have been emphasized by increasing works of research, the impacts that may be posed by these practices on the environmental sustainability of manufacturing companies are not unexpected. Nevertheless, GSCM is capable of improving the performance of manufacturing firms in various aspects. Pertaining to this, this research aims to explore the application of GSCM practices and the effects they pose on organizational performance. To be specific, in this study, the results of the application of a set of internal and external GSCM practices on various aspects of organizational performance were investigated. Furthermore, according to the data collected, which were from 121 food, pharmaceuticals survey questionnaires, and chemical manufacturing companies in Palestine, statistical analyses were conducted. Moreover, partial least squares structural equation modeling (PLS-SEM) was utilized for the assessment of the hypotheses associated with the application of the internal and external GSCM practices and organizational performance. However, the findings of this research will be important specifically for the manufacturing organizations which aim for the enhancement of their organizational performance.
\end{abstract}

Index Terms: Green supply chain Management, Environmental performance, Operational performance.

\section{INTRODUCTION}

As environmental sustainability gains accumulating interest and awareness, companies are forced to put more emphasis on the implications posed by their industrial footprints on the environment [1]. Additionally, high polluting industries are dealing with more pressures in this matter. Besides, manufacturing is one of the fields where the highest amount of workforce is used and the most significant effects and footprint are put on the community. Overall, due to the impacts the manufacturing industry poses on the society, environment, and the economy, opportunities for participation in encouraging and contributing to

Revised Manuscript Received on April 25, 2019.

Ahmed A. Zaid, Department of Industrial Management, Faculty of Business and Management, Palestine Technical University - Kadoorei, 7, Tulkarem, Palestine.

Abdul Talib Bon, Department of Production and Operations Management, Faculty of Technology Management and Business, Universiti Tun Husein Onn Malaysia (UTHM), 86400, Batu Pahat, Malaysia.

Ayham A.M. Jaaron, Department of Industrial Engineering, Faculty of Engineering, An-Najah National University, 7, Nablus, Palestine.

sustainability are provided by the manufacturing industry [2]. As a result, green supply chain management (GSCM) practices are becoming a widely known management strategy for solving issues related to the environment [3]. GSCM refers to all stages of supply chain management that should be in accordance with the requirements for the environmental protection [4]. These practices can be widely categorized into intra- and inter-organizational environmental practices where supply chain members need to work with one another [5]. Therefore, the organization is generally a part of the supply chain and they should pay attention to the practices performed by other members, including what is expected of the stakeholders [6]. Those expectations are associated with the socially and environmentally accountable practices and principles. In addition, through these aspects, the main focus of the analysis of today's business requisite is represented [6].However, the application of GSCM practices by manufacturing organizations is still low in developed countries due to the lack of awareness of the importance of maintaining the business $[7,8]$. To illustrate this, in Palestine, the manufacturing industry has the largest contribution to the pollution index of this country [9]. Significant improvement in the protection and sustainable development of the environment can be made through any efforts of putting the environmental footprints of this industry at a minimum. Therefore, this study was performed on the manufacture of organizations with the objective to experiment on how far GSCM practices are applied and the results of the application in the aspect of maintainable performance. Moreover, no definite conclusion was made from the empirical studies' results on the effects that GSCM practices pose on organizational performance. To illustrate this point, it was highlighted by Zhu et al. [10, 11] that GSCM practices have not brought improvement in the economic performance of Chinese manufacturing companies. This was because the concept of these practices implementation was in its early phases in those two researches. The early stage was known as adoption. This stage usually needed an investment which will raise the operational costs sustained by organizations and pose a negative effect on their economic adyantages On $_{\dot{g}_{i}}$ the other

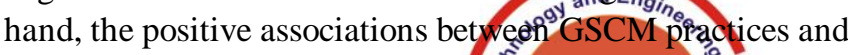
the organization's economic performance have been 


\section{The Impact of Implementing External and Internal GSCM Practices on Organizational Performance: Evidence from Manufacturing Firms in Palestine}

investigated by current research (e.g. [12, 13]).

The combination of these results and the importance of a further understanding of the relationship between generalized GSCM practices and organizational performance had become the basis of this study. This empirical generalization holds an essential importance due to the different application methods of GSCM practices. Therefore, this study aims to offer empirical generalizations on the association between GSCM practices and organizational performance. Based on this research purposes, the content of this article is organized as follows: The next section of this article draws on the theoretical framework of this study and a collection of hypotheses. This is followed by the methodology section which elaborates on the essential components of this study. This study's results will be written along with explanations on them. This article ends with conclusions on the essential contributions and limitations of this study, including recommendations for possible improvements in future works of research.

\section{THEORETICAL FRAMEWORK AND HYPOTHESES DEVELOPMENTED}

The increasing dangerous impact posed by manufacturing companies is overcome by the increasing prominence of GSCM [14]. For this reason, on top of other sustainability performance, GSCM is taken as an efficient, strategic management that contributes to the improvement of the environmental performance of the manufacturing organizations [15]. This point is supported by De Giovanni [16], who points out that GSCM is not only a method to reduce the environmental footprints of operations and products, it is also a unique approach which offers economic advantages, including the improvement of the social welfare. Accordingly, GSCM practices are usually described as the initiatives needed for the incorporation of environmental principles and values throughout the procedures of the supply chain [17]. In performing these initiatives, both internally and externally oriented practices need to be performed [18]. Therefore, pertaining to the current insights provided by the aforementioned literature on the supply chain, this study takes the practices of environmental management into account. As for these practices, besides green purchasing (GP) and reverse logistics (RV), partial cooperation and transaction between suppliers and customers are required as external GSCM practices [19]. On the other hand, the activities which do not require the involvement of direct customer, supplier, or internal environmental management (IEM) and eco-design (ECO) are taken as internal GSCM practices which can be applied and managed by an individual manufacturer [19]. Besides, there have been numerous adoptions and discussions made in previous works of literature on these practices [20, 21]. Additionally, besides providing a competitive advantage, the adoption of these two sets of intra- and inter-organizational green practices is possible by any members in the supply chain either on the upstream or downstream side of the chain [22].

Theoretically, there are many ways of exploring the association between GSCM practices and the manufacture of organizational performance [14]. This makes organizational performance a concept with various aspects. According to Paauwe [23], in the application of GSCM practices on the aspect of the operational, social, economic, and environmental performances of organizations, the "organizational performance" in the current study is described as the real output. Pertaining to the discussion in this section, the next section will discuss the association between the elements of organizational performance and GSCM (i.e., external and internal GSCM) practices.

\section{A. GSCM practices and Organizational Performance}

GSCM practices are developed with its main objective to enhance the environmental performance (EP) of manufacturing organizations [21]. Furthermore, the implementation of external and internal practices is with the aim towards the positive impacts on EP [24]. The positive association between GSCM and EP has been shown in past works of research, and this has been proven by works of evidence from manufacturing industries which illustrated that positive associations between GSCM practices and EP outcomes stem from various GSCM practices [18, 21, 25]. As an example, Zhu and Sarkis [11] and Zhu et al. [10] found that internalGSCM practices positively impact the EP, from putting the consumption of hazardous and toxic materials at a minimum, to reducing the accumulation of waste. Additionally, Green et al. [24] postulated the improvement of the EP of the manufacturing industries in the US context can be achieved through internal GSCM practices such as IEM and ECO.

In respect with external GSCM practices, Diabat et al. [25] and Green et al. [24] found that external GSCM practices and EP stem from the positive association between RL, GP, and cooperation with customers. Apart from that, it has been proven in other works of research that EC and green procurement encourage suppliers and customers to display environmentally friendly actions way and reduce any unsustainable actions. Consequently, these contribute to positive effects on the EP of the manufacturing organizations $[18,26]$. By offering education and monitoring programs to the suppliers, organizations will definitely be provided with assistance in the provision of materials included in the final product that minimalize environmental pollution. As a result, this will enhance the EP of the organizations [26]. Accordingly, several hypotheses have been formulated, which are as follows:

H1 : GSCM practices pose positive impacts on EP.

H1a : External GSCM practices pose positive impacts on EP. $\mathrm{H} 1 \mathrm{~b}$ : Internal GSCM practices pose positive impacts on EP.

As of currently, it has been found by numerous empirical studies that there is a positive association between GSCM practices and economic performance (Ec.P) that can bring a competitive advantage for the organflations [27-29], particularly the manufacturing organizations in eveloping countries [7]. 
Furthermore, the importance of Ec.P can be seen more clearly. To illustrate this point, manufacturers have put the adoption of proactive strategies (e.g. cleaner production and green management including GSCM) into consideration for the improvement of the organization's economic performance [4].

Aside from the reduction of resource use, high efficiency can be achieved by the organizations. This can save total cost, specifically through the focus on internal GSCM where eco-friendly manufacturing practices are done [18, 29]. For example, it was found by Koh et al. [28] that the minimization of waste and effective material use can be seen from ECO which is an element of the internal GSCM practices. These practices can save cost, which can give positive impacts to the Ec.P of the organizations. Similarly, a positive association between ECO practices and cost minimization was discovered by Sroufe [30] through the enhanced probabilities of product sale in international markets, as well as the qualities that overcome costs.

It was also proven that external GSCM practices pose a positive effect on the Ec.P of the organizations [11, 21, 25]. To illustrate this point, it was highlighted by Gimenez et al. [18] that the improvement of efficiency, including the reduction of operational costs, stems from the EC and their supplier's result. This occurs specifically due to the reduction of waste during the processes of manufacturing. Furthermore, an advantage in terms of diversity, which provides positive impacts on an organization's sales and revenue, can be obtained by the organizations. This is with the acts of putting the environmental impacts posed by their products on the minimum via internal and external GSCM, disposing of harmful product constituents, and reducing the use of toxic materials [31]. Meanwhile, it was found by Holt and Ghobadian [32] that external GSCM practices, such as GP, will bring benefits in terms of economic performance (sales and market share, increase in profit, and cost savings). Similarly, Carter et al. [33] emphasized that there is a relationship between GP and the increase in net income and decrease in the cost of sold products. Accordingly, several hypotheses have been formulated, which are as follows:

H2 : GSCM practices pose positive impacts on Ec.P.

$\mathrm{H} 2 \mathrm{a}$ : External GSCM practices pose positive impacts on Ec.P.

$\mathrm{H} 2 \mathrm{~b}$ : Internal GSCM practices pose positive impacts on Ec.P.

It is believed that the improvement of the working environment for employees and the community can be achieved by adopting the green practice which reduces pollution. With this, a healthier life can be sought by people [34]. Furthermore, by conducting environmentally-oriented manufacturing operations which reduce pollution, a positive impact can be achieved, specifically on the social aspect of organizations that emphasize on staff and society, as mentioned by Elkington [35]. To support this point further, De Giovanni [16] stated that a number of social targets, such as the protection of customers, market transparency, and environmental preservation, can be achieved by the organizations. Therefore, positive contributions to social performance (SP) can be made by the organizations that adopt GSCM into their businesses.

Despite the limitations in the number of empirical research works on the association between SP and GSCM practices shown in previous works of GSCM literature, it can be seen from the existing empirical evidence that eco-friendly practices generally exhibit decent social performance, such as gaining loyalty from customers [16] and improving corporate image [36]. Accordingly, several hypotheses have been formulated, which are as follows:

H3 : GSCM practices pose positive impacts on SP.

$\mathrm{H} 3 \mathrm{a}$ : External GSCM practices pose positive impacts on SP. $\mathrm{H} 3 \mathrm{~b}$ : Internal GSCM practices pose positive impacts on SP.

The positive association between GSCM practices and operational performance (OP) has been discovered by a large number of empirical research works in the Asian countries (e.g. [37-41]). By adopting GSCM practices, the effectiveness of the processing and recycling of waste can be improved, the penalties inflicted by the environment department of the government can be prevented, and the costs of compliance can be eliminated in the future [38]. Moreover, it was found by Lee et al. [40] that with GSCM practices, operational effectiveness can be enhanced. This enables companies to perform the reduction on several items, such as delivery time, scrap rate, and inventory levels, hence improving OP. Provided the discussions above, several hypotheses have been formulated, which are as follows:

\section{H4 : GSCM practices pose positive impacts on OP.}

H4a : External GSCM practices pose positive impacts on OP. $\mathrm{H} 4 \mathrm{~b}$ : Internal GSCM practices pose positive impacts on OP.

The framework of the current study is presented graphically in Fig. 1 where the study hypotheses are added. The theoretical framework was empirically tested in the context of Palestine. It includes direct effects from internal and external GSCM practices towards components of organizational performance (i.e. EP, Ec.P, SP and OP).

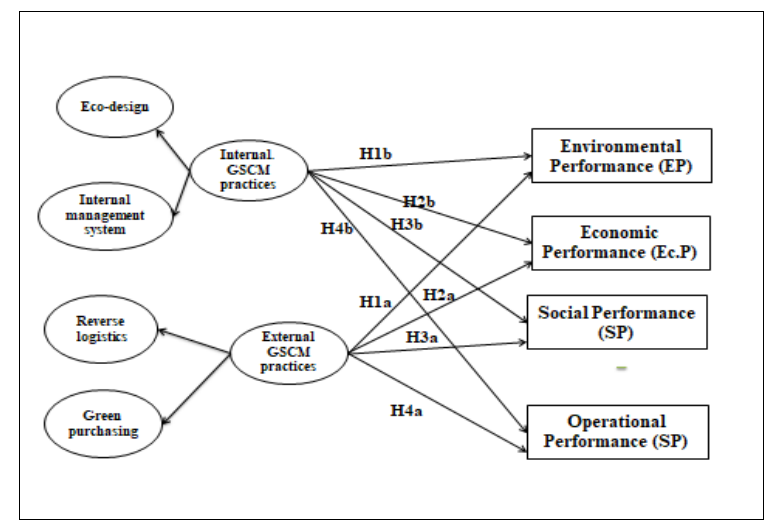

Fig. 1. Conceptual framework.

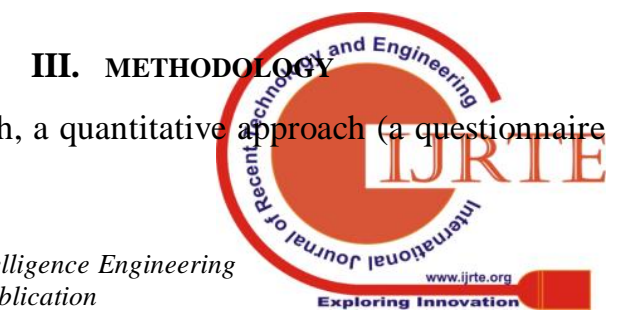




\section{The Impact of Implementing External and Internal GSCM Practices on Organizational Performance: Evidence from Manufacturing Firms in Palestine}

survey) was applied as this method is capable of obtaining a larger set of data from a population. Besides, a better analysis of the impacts that one variable pose on another variable can be conducted. This research aimed to put the following hypothesis to test, which is: accurate data is created by the associative form which is according to measurable empirical phenomena.

This research also managed to evaluate this hypothesis to detect the presence of doubt associated with the validity of theory and knowledge. Additionally, the evaluation was conducted through statistical depiction, predictive relationships, the construction of data and facts, theoretical testing, and clarity.

\section{A. Survey Design and Sampling}

The population chosen for this research consisted of the manufacturing organizations in the industrial sectors with the highest pollution rate (i.e., chemical, food, and pharmaceuticals industries) in Palestine from 2017 to 2018. First and foremost, in order to gain general data regarding these manufacturing organizations such as organization's name, the year of foundation, location, the number of employees, contact information, and many others, the Palestinian Federation of Industries (PFI) was contacted. PFI stated that the total number of existing organizations was 220. However, in meeting this research objective, the criteria for the organization participation were made, where one of them was that they applied green practices in their manufacturing activities. Then, to reconfirm on the implementation of green practices and its extent in the organizations, contact was made to each organization's supply chain manager (the study survey respondents) through telephone calls. This was followed by the distribution of surveys in an electronic format. Initially, it was believed that supply chain managers were capable of providing information which most accurately reflects the actual situation of the organization, particularly the variables required in this research for the evaluation of the hypothesized relationships. As a result, 160 out of manufacturing organizations implemented GSCM practices and agreed for participation in this research. Following that, five supply chain managers and expert practitioners were appointed for a pilot test on the consistency and validity of this research questionnaire before it was distributed. The pilot-testing procedures, as deemed necessary by Masri and Jaaron [9], allowed this study for rearrangement of particular elements, therefore proving to be useful in this research. The collection of data dated from November 2017 to January 2018 was performed through web-based surveys. The distribution of surveys was done through email to the supply chain managers in all of the participating manufacturing organizations. The distributed structured questionnaires were 160 in total, where 121 complete responses were given by supply chain managers, amounting to $75.62 \%$ response rate. According to Hair et al. [42], 121 are considered a sufficient sample size for the data analysis using SEM-Partial Least Squares (PLS). It is worthy of noting that this data-set was within the limits set by one of this research criteria, where the sample size should be larger than the highest number of structural paths directed towards any construct by 10 times at minimum [43].

\section{B. Measurement of Constructs}

The internal and external GSCM practices were put into use in this research as the second-order reflective constructs with first-order dimensions [44]. These constructs were modeled as reflective instead of formative because doing this brought consistency with the method of modeling performed in the past works of research. Previously, it was found that the first-order dimensions of each construct were covered with each other. They also had the same theme, and the conceptual domain of the second-order construct was measured by all of them [45]. However, the measurement of the external GSCM practices was done by the three first-order dimensions of GP, EC, and RV. To be specific, the external GSCM was distinguished by reflective scales where these three dimensions were measured on GSCM. Meanwhile, the measurement of the internal GSCM practices was done by the two first-order dimensions of IEM and ECO. On the other hand, the internal GSCM was distinguished by reflective scales where these two dimensions were measured on GSCM. As for the organizational performance items (i.e., EP, Ec.P, SP, and $\mathrm{OP})$, perceptual measures of organizational performance were recorded. To fulfill the requirements of validity and reliability, the measures were displayed [46]. Additionally, with the five-point Likert scales, the adaptation of scale items for all constructs was performed using the existing scales. Figure 1 displays the theoretical model of the internal and external GSCM.

\section{DATA ANALYSIS AND RESULT}

For the assessment of H1, H2, H3, and H4, A PLS-SEM analysis method was applied where the Smart-PLS 3.2.7 software was used. In fact, this is a second-generation multivariate analytical instrument used for the discovery of new theories. In this research, the theory was associated with GHRM, with Palestine as the context. Furthermore, SEM-PLS is capable of the simultaneous identification of both the hypotheses and the statistical properties of a conceptual framework [42]. The use of this analysis method is prevalent in many types of management studies [47].

\section{A. Measurement Validation}

Based on Table 1, the components of organizational performance (i.e., EP, Ec.P, SP, and OP), the internal GSCM practices, and the measurement scales of the reflective constructs for external GSCM practices are illustrated. In identifying the internal consistency and the convergent validity of the eleven reflective constructs (the loading of the item, the construct's composite reliability (CR) and average variance extracted (AVE)), three assessments were conducted. It was found that the indicators for all of the item loadings ranged from 0.740 to 0.927 , while the posited underlying construct factor of them turned out to go beyond 0.7. Furthermore, the CRs of these constructs were higher and Engin IJTRT 
than the initial CR obtained by Nunnally and Burstein [48] which was 0.7. Meanwhile, they displayed higher AVEs compared to the suggested starting value which was 0.5 . This fulfilled the convergent validity that was addressed by Fornell and Larcker [49]. For a more detailed checking of discriminant validity, a squared correlation was created between the two latent constructs and their AVE estimates [49]. In fact, these constructs fulfilled the requirements of the validity of the AVE estimates, which subsequently transcended the squared correlation between each pair of constructs (see Table 2).

In accordance to the suggestion made by Henseler at al. [50], checking was also conducted on the discriminant validity through the heterotrait-monotrait ratio (HTMT). As a result, it was shown that HTMT displayed lower ratios than the restricted ratio which was 0.85 . $\mathrm{T}$

his indicates the properties of a healthy discriminant validity, which is shown in Table 3 below.

Table 1. Results of the Measurement Models.

\begin{tabular}{|l|l|l|l|}
\hline Constructs & Factor Loading & CR & AVE \\
\hline Eco-design & 0.818 & 0.873 & 0.579 \\
\hline $\begin{array}{l}\text { Internal environmental } \\
\text { management }\end{array}$ & 0.934 & 0.948 & 0.753 \\
\hline Green purchase & 0.924 & 0.943 & 0.768 \\
\hline $\begin{array}{l}\text { Environmental } \\
\text { cooperation }\end{array}$ & 0.940 & 0.953 & 0.771 \\
\hline Reverse Logistics & 0.816 & 0.889 & 0.728 \\
\hline $\begin{array}{l}\text { Environmental } \\
\text { performance }\end{array}$ & 0.940 & 0.954 & 0.806 \\
\hline Economic performance & 0.935 & 0.948 & 0.721 \\
\hline Operational performance & 0.935 & 0.949 & 0.755 \\
\hline Social performance & 0.910 & 0.933 & 0.736 \\
\hline
\end{tabular}

Table 2. The Discriminant Validity of Measurement Model

\begin{tabular}{llllllllll}
\hline Const & Ec.P & EC & ECO & EP & Ec.P & GP & IEM & OP & RV \\
\hline EC & 0.87 & & & & & & & & \\
ECO & 0.68 & 0.76 & & & & & & & \\
EP & 0.66 & 0.56 & 0.89 & & & & & & \\
Ec.P & 0.62 & 0.64 & 0.69 & 0.84 & & & & & \\
GP & 0.74 & 0.62 & 0.61 & 0.57 & 0.87 & & & & \\
IEM & 0.72 & 0.72 & 0.69 & 0.66 & 0.71 & 0.86 & & & \\
OP & 0.64 & 0.62 & 0.84 & 0.73 & 0.60 & 0.69 & 0.86 & & \\
RV & 0.48 & 0.58 & 0.39 & 0.45 & 0.35 & 0.44 & 0.33 & 0.85 & \\
SP & 0.66 & 0.66 & 0.80 & 0.69 & 0.63 & 0.73 & 0.75 & 0.45 & 0.85 \\
\hline
\end{tabular}

Table 3. Heterotrait-Monotrait Ratio

\begin{tabular}{llllllllll}
\hline Construct & EC & ECO & EP & Ec.P & GP & IEM & OP & RV & SP \\
\hline EC & & & & & & & & & \\
ECO & 0.77 & & & & & & & & \\
EP & 0.70 & 0.63 & & & & & & & \\
Ec.P & 0.66 & 0.73 & 0.74 & & & & & & \\
GP & 0.79 & 0.70 & 0.65 & 0.61 & & & & & \\
IEM & 0.77 & 0.81 & 0.74 & 0.70 & 0.76 & & & & \\
OP & 0.68 & 0.70 & 0.80 & 0.78 & 0.65 & 0.73 & & & \\
& & & & & & & & &
\end{tabular}

\begin{tabular}{llllllllll}
$\mathrm{RV}$ & 0.53 & 0.70 & 0.43 & 0.49 & 0.38 & 0.49 & 0.35 & \\
$\mathrm{SP}$ & 0.71 & 0.76 & 0.77 & 0.74 & 0.68 & 0.79 & 0.81 & 0.51 \\
\hline
\end{tabular}

\section{B. Estimation Model}

Based on Table 4, the PLS findings for the estimation models are displayed. The findings consist of standardized path coefficients, with the significance according to the two-tailed t-tests for this research hypothesis. As for the assessment of the strength and quality of the structural model estimate, it was conducted according to the instructions by Peng and Lai [47]. This assessment started with the structural model where the use of the bootstrap procedure was involved. In this step, 1000 rounds of resampling were done, and as a result, a consistency was found in the magnitude and the significance of the structural paths. The second step was the Stone-Geisser's $\mathrm{Q}^{2}$ test $[51,52]$, which was conducted for the assessment of the model's predictive relevance (see Table 4), provided that the indication of the accepted predictive relevance was based on the result of $\mathrm{Q}^{2}>$ 0 for all endogenous constructs. The third step was the calculation of the relative effect sizes $\left(\mathrm{f}^{2}\right)$ of the exogenous constructs through Cohen's equation [53]. From this procedure, it was found that the sizes of all $\mathrm{f}^{2}$ figures were relatively high. The fourth step was the goodness of fit $(\mathrm{GoF})$ test, which was performed to evaluate the research model's quality as a whole. It also aimed to display the complete structural model's quality in the aspect of average $\mathrm{R}^{2}$ (refer to Table 4). As a result, the value of the GoF was 0.642. Overall, the adjusted variance according to the EP, Ec.P, OP, and SP ( $\mathrm{R}^{2}$ adjusted) amounted to $0.519,0.513,0.523$, and 0.590 , respectively.

Table 4. $\mathrm{R}^{2}$ and effect size

\begin{tabular}{|c|c|c|c|c|c|c|}
\hline Construct & $\mathbf{R}^{\mathbf{2}}$ & $\mathbf{Q}^{\mathbf{2}}$ & $\mathbf{f}^{\mathbf{2}}(\mathbf{E P})$ & $\mathbf{f}^{\mathbf{2}}(\mathbf{E C . P})$ & $\mathbf{f}^{\mathbf{2}}(\mathbf{O P})$ & $\mathbf{f}^{\mathbf{2}}(\mathbf{S P})$ \\
\hline Internal GSCM & ----- & 0.53 & 0.109 & 0.165 & 0.183 & 0.240 \\
\hline External GSCM & ----- & 0.48 & 0.096 & 0.050 & 0.046 & 0.059 \\
\hline EP & 0.51 & 0.39 & ----- & ---- & --- & --- \\
\hline Ec.P & 0.51 & 0.33 & ---- & ---- & ----- & --- \\
\hline OP & 0.52 & 0.36 & ---- & ---- & ---- & --- \\
\hline SP & 0.59 & 0.39 & ----- & ----- & ---- & --- \\
\hline
\end{tabular}

Referring back to the set of hypotheses shown in the previous section, it is indicated in Table 5 that H1a and H1b: $(\beta=0.370, p<0.05 ; \beta=0.394, p<0.05)$ supported the association between external GSCM practices, internal GSCM practices, and EP. Out of all practices, internal GSCM practices were the only practice which had a positive association with Ec.P $(\beta=0.488, p<0.05)$. Meanwhile, there was no association between the external GSCM practices and Ec.P $(\beta=0.269, p>0.05)$, which explained the support to $\mathrm{H} 2 \mathrm{~b}$ instead of $\mathrm{H} 2 \mathrm{a}$. The internal GSCM had the same case, where it had a positive association with SP $(\beta=0.540, \mathrm{p}<0.000)$, which explained its support to $\mathrm{H} 3 \mathrm{~b}$ instead of $\mathrm{H} 3 \mathrm{a}$. As for $\mathrm{OP}$, it was shown by the results that the external and internal GSCM had a positive relation to OP and EP $(\beta=0.254, \mathrm{p}<$ $0.05 ; \beta=0.508, p<0.000)$, which explained the support to $\mathrm{H} 4 \mathrm{a}$ instead of $\mathrm{H} 4 \mathrm{~b}$. 


\section{The Impact of Implementing External and Internal GSCM Practices on Organizational Performance: Evidence from Manufacturing Firms in Palestine}

\section{DISCUSSION AND FINDINGS}

Based on past works of literature, it can be seen that GSCM practices and organizational performance are two SCM concepts which are related to each other. This is because based on numerous works of research performed; the prominent association between these two constructs is evident $[32,54]$. Based on the final result from the empirical data analysis, it was shown that the varying results displayed by the GSCM - organizational performance association. This is possibly due to the insufficiency of expertise, knowledge, flexibility, time, money, resources, skills, and many other factors relating to the organization's size [55]. Another possible factor is that the issue regarding the adoption of GSCM practices in the Palestine context is still recent. According to Huang et al. [56], globalization and the advantages of the experiences gained from international organizations in GSCM fields can gradually resolve this issue. With this, the enhancement in GSCM practices is not uncommon. The second factor of this issue can be seen from the simultaneous balance between organizational performance and the application of the internal and external GSCM practices [21, 57, 58]. This indicates that GSCM practices are worthy to be focused upon by manufacturing organizations as the elements of compromise between EP, Ec.P, SP, and OP [29, 59, 60].

In respect to Ec.P, it can be seen from the findings that the only practice with a positive association with Ec.P was the internal GSCM practices. From this observation, it is indicated that the improvement in Ec.P mainly requires the implementation of internal GSCM practices. Besides, environment-wise, this improvement in the organization in Palestine stems from the internal GSCM practices. Therefore, these practices hold a significant role in Palestinian organizations, especially those with insufficient resources and needing to see economic advantages in a short period of time. In fact, when it comes to the implementation of inputs and assets, the internal GSCM practices and improvement in efficiency of production processes are related to each other, which in turn contributes to reduced costs through product recycling, the conservation of energy [10, 11], the decrease of waste and re-cycling [61], and the enhanced quality of production processes including the design of products [62].

On the other hand, the association between Ec.P and the external GSCM practice was rather ordinary. This is due to a number of possible factors. The first factor can be seen from the condition of the manufacturers in Palestine, where their implementation of GSCM practices is still in the early phase. Secondly, before Ec.P takes on a prominent effect from the external GSCM practices, it might take longer for the effect of some of these practices (e.g. RV) to surface [63]. To illustrate this, it has been shown in a research from the past that the payback duration for several cases of ecological practices and change of process is longer [64]. Besides, De Giovanni [16] asserted that neither a positive or negative effect can be seen from the Ec.P of the organization within a short period of time when sustainability programs are implemented. As for the third factor, a significant amount of investment is needed for the organization in order to conduct contamination control. The investment is used specifically for the organization's production greening and operation procedures especially in a number of external GSCM practices such as RV [63]. As a result, the improvement of organization's Ec.P will not be achieved despite the improvement of the organization's improved ecological situation [65]. The last factor is definitely the contradictory impact caused by the choosing of suppliers and monitoring them, and working with them.

Although the negative effect will be shown in a short period of time, it will be positive for the long period of time [66]. To illustrate this point, with the choosing, monitoring, and working with the suppliers, the increase in sales can be achieved through the rise of the organization's reputation. However, for those actions to be performed, a relational investment with suppliers may be needed by the organization, including the advantages such as reduced costs or higher revenue, which cannot be achieved within a short time. Besides, provided the willingness of suppliers for environment-related investments, there will be a rise in the purchasing price for the main organization within a short period of time [59]. The identification of environmental efficiencies and the basis of the organization's EP improvement can be obtained through a proper EP that stems from positive environmental practice. Therefore, the disposal of waste will result in a higher EP of manufacturing organizations [67]. Huang et al. [56] showed the direct association between internal GSCM practices, such as IEM, and ecological context. These practices contribute to the betterment of the organization's EP through reduced contamination and resource use. Abdullah [63] supported this argument by highlighting that manufacturing organizations will be able to conserve energy and reduce a significant amount of waste by using eco-friendly products, which ultimately improves EP. These findings actually hold a huge importance because with the use of eco- friendly products, the quality of EP is definitely assured [68]. Tynon [69] and Jabbour et al. [57] studies have proven the positive effects that the external GSCM practices pose on EP's quality. It was suggested in these studies that the estimation of EP is possible through external GSCM (i.e., GP and EC) practices and the integration of ecological criteria into the procedures of supplier selection. Furthermore, it is true that the internal and external GSCM are two inter-reliant set of practices. To illustrate this point, the demand for product designing stage is the main factor of GP [63]. Besides, it was emphasized by Tseng et al. [70] that the cooperation between manufacturers and suppliers in creating the environmental design of the products is highly important, especially during the early phases of research and development. In this case, the organization's environmental requirements can be fulfilled by the suppliers, provided that they show their awareness of the environment through the use of eco-friendly materials and packaging [11].

In respect to SP, GSCM practices play their roles by reducing negative environmental effects. Besides, these practices commonly have the essential role of improving the image of the organization in front of the stakeholders (e.g employees, suppliers, clients, and the government) [71].

Furthermore, the organization can achieve numerous advantages social-wise, such as

Published By.

Blue Eyes Intelligence Engineering 
the improvement of employees' morals and the loyalty and satisfaction of customers, through the presence of positive image [36]. Nevertheless, the slight impact posed by the external GSCM practices on SP is shown in this research. Meanwhile, Geng et al. [14] discovered several analogous results, where the positive effect on the SP of manufacturing organizations in the context of developing economies Asia is due to a part of the external GSCM practices, which is the RV. There are two possible factors to this. The first factor is the culture instilled in the developing Asian economies, where recycling is not really implemented. This practice is seen as unrealistic by the industrial manufacturers in this continent [14]. Similarly, it was highlighted by Lai et al. [72] that the cooperation between these manufacturers and suppliers and stakeholders is important in order to determine a number of external GSCM practices (i.e., recycling) that can lead to the improvement of the organization's SP. The second possible factor is the implementation of the external GSCM practices, which is insufficient to obtain better results [73]. This argument is supported by Laosirihongthong et al. [27], who mentioned that several types of external GSCM practices (i.e., EC) are not associated with SP due to the absence of awareness among most manufacturers in Asia regarding the effectiveness of this type of practice for an improved organization's image. On the contrary, a significant and solid relationship was found between the internal GSCM practices and SP. In other words, the organization's SP improved through the implementation of these practices. This correlation is rather common, provided that the application of the internal GSCM practices was widespread in Palestine before the external GSCM practices were applied. Meanwhile, SP possessed the highest achievement rate. According to Epstein and Buhovac [74], with the development of social responsibility programs, the organizations can improve their sales, gain loyalty from customers and build a positive image. Besides, with these programs, the organizations will be able to increase their competency in the field of social development. Confirmation has been made in previous works of research that the morals of employees in the organization will be influenced positively with the provision of an ergonomic working condition by the organizations. This, in turn, will have a positive outcome on the organization's reputation, which will eventually impact the clients who possess organization image, brand, reputation, and loyalty. $[71,75]$. Therefore the organizations contribute to the improved products quality and productivity [63].

Finally, when it comes to OP, it was mentioned by Ann et al. [76] that operational timesaving and improvement of production quality are not the results of the application of intra-organizational environmental management. However, most of the research works from the past have illustrated that for the enhancement of $\mathrm{OP}$, intra-organizational environmental management is an efficient and wide-ranging mechanism $[11,77]$. Additionally, it was found by Lai et al. [72] and Yang et al. [62] that implementing intra-organizational environmental management practices can contribute to the improvement of OP in the aspect of time of delivery and quality of goods. In accordance with this, intra-organizational environmental management makes the cross-functional cooperation possible and eliminates the functional barriers of manufacturing processes [11]. Therefore, with this management, an improved collaboration on production capacity is possible, particularly for the improvement of operational effectiveness and flexibility [78]. Apart from that, the adoption of environmental awareness into the development of goods and the phases of designing contributes to the improvement of OP [79]. Similarly, input and collaboration between suppliers and customers are the sensitive factors of OP [38]. For this reason, through the incorporation of suppliers and cooperation provided by customers, on-time delivery is possible, which contributes to improve OP [80].

\section{CONCLUSION}

This study aims to provide a step forward in the understanding of how manufacturing organizations can improve their performance in sustaining the environment by implementing GSCM practices. Pertaining to this objective, the complex association between the external GSCM practices has been investigated. This was done by putting particular focus on RV, EC, GP, the internal GSCM practices, IEM and ECO, and the elements of organizational performance (i.e., OP, SP, Ec.P, and EP). It is expected that effective GSCM practices can contribute to the improvement in the manufacturing organization's role in the society. Apart from that, there are significant advantages to be gained by these organizations from the aforementioned practices. Therefore, it has been suggested that GSCM practices are the efficient methods to increase the range of responsibility of business organizations.

To summarize, all elements in the supply chain play a role in the GSCM practices. These elements are with the suppliers and customers included. Based on the overall research findings, it has been indicated that GSCM holds a potential as an area of research and practice. It only requires more detailed works of research in order to provide more insights into the factors and methods of implementing the GSCM practices in today's competitive world. Moreover, recommendations have been made by the researchers, which are as follows: 1) proceed the coordination between different administrative levels for the application of the green supply chain to obtain the best GSCM practices, 2) seek for the most environmental-friendly raw materials to be utilized in the food industry, 3) continue conducting environmentally safe designing and packaging, 4) formulate the plan for annual employee training which fulfills the training needs of the workers. These needs have an association with the green supply chain, 5) raise the allocated budget for scientific studies in the green supply chain field, and 6) enact governmental regulations and conditions in order to improve the environment in terms of security. 
The Impact of Implementing External and Internal GSCM Practices on Organizational Performance: Evidence from Manufacturing Firms in Palestine

Table 5. Results of PLS Model

\begin{tabular}{|l|l|l|l|l|}
\hline Hyp. & Path.Coef. & T- value & P-value & Result \\
\hline H1a & 0.370 & 3.207 & 0.001 & Supported \\
\hline H1b & 0.394 & 3.198 & 0.001 & Supported \\
\hline H2a & 0.269 & 1.706 & 0.088 & Not Supported \\
\hline H2b & 0.488 & 3.376 & 0.001 & Supported \\
\hline H3a & 0.268 & 1.9 & 0.058 & Not Supported \\
\hline H3b & 0.540 & 3.973 & 0.000 & Supported \\
\hline H4a & 0.254 & 2.027 & 0.043 & Supported \\
\hline H4b & 0.508 & 4.205 & 0.000 & Supported \\
\hline
\end{tabular}

\section{ACKNOWLEDGMENT}

A special thanks for Palestine Technical University -Kadoorei for supporting this research.

\section{REFERENCES}

1. M. Tseng, R. Tan and A. Siriban-Manalang, "Sustainable consumption and production for Asia: sustainability through green design and practice" Journal of Cleaner Production, vol. 40, pp. 1-5, 2013.

2. R. Cagliano, R. Golini and A. Longoni, "The role of NFWO in sustainability strategies: an OM perspective". In International Annual EurOMA Conference, 2010

3. R. Abdullah, M. Hassan and N. Johari, "Exploring the Linkage of Supply Chain Integration between Green Supply Chain Practices an Sustainable Performance: a Conceptual Link". In $4^{\text {th }}$ International Conference on Future Environment and Energy, pp. 116-120, 2014.

4. Q. Zhu and J. Sarkis, "The moderating effects of institutional pressures on emergent green supply chain practices and performance." International journal of production research., vol. 45, no. 18, pp. 4333-4355. 2007.

5. B. Flynn, B. Huo and X. Zhao, "The impact of supply chain integration on performance: A contingency and configuration approach.” Journal of operations management., vol. 28, no. 1, pp. 58-71, 2010.

6. A. Ashby, M. Leat andM. Hudson-Smith, "Making connections: a review of supply chain management and sustainability literature." Supply Chain Management International Journal., vol. 17, no. 5, pp. 497-516. 2012.

7. H. Younis, B. Sundarakani and P.Vel, "The impact of implementing green supply chain management practices on corporate performance". Competitiveness Review., vol. 26, no. 3, pp. 216-245, 2016.

8. S.M. Diab, F.A. AL-Bourini and A.H. Abu-Rumman, "The impact of green supply chain management practices on organizational performance: a study of jordanian food industries." Journal of Management and Sustainability., vol. 5, no. 1, pp. 149-157, 2015.

9. H. Masri and A. Jaaron, "Assessing green human resources management practices in Palestinian manufacturing context: An empirical study. Journal of cleaner production., vol. 143, pp. 474-489, 2017.

10. Q. Zhu, J. Sarkis and Y. Geng. "Green supply chain management in China: pressures, practices and performance." International Journal of Operations \& Production Management., vol. 25, no. 5, pp. 449-468, 2005.

11. Q. Zhu and J. Sarkis, "Relationships between operational practices and performance among early adopters of green supply chain management practices in Chinese manufacturing enterprises." Journal of operations management., vol. 22, no. 3, pp. 265-289, 2004.

12. C. Kuei, W. Chow, C. Madu and J. Wu, "Identifying critical enablers to high performance environmental management: an empirical study of Chinese firms." Journal of environmental planning and management,.., vol. 56, no. 8, pp. 1152-1179, 2013

13. K. Lai and C. W. Wong, "Green logistics management and performance: Some empirical evidence from Chinese manufacturing exporters." Omega, vol. 40, no. 3, pp. 267-282, 2012.

14. R. Geng, S. A. Mansouri and E. Aktas, "The relationship between green supply chain management and performance: A meta-analysis of empirical evidences in Asian emerging economies" International Journal of Production Economics., vol. 183, pp. 245-258, 2017.

15. M. Hassan, R. Abidin, N. Nordin and R. Z. Yusoff, "GSCM practices and sustainable performance: A preliminary insight." Journal of Advanced Management Science., vol. 4, no. 5, pp. 430-434, 2016.
16. P. De Giovanni, "Do internal and external environmental management contribute to the triple bottom line?" International Journal of Operations \& Production Management,. vol. 32, no. 3, pp. 265-290, 2012.

17. S. Srivastava, "Green supply-chain management: a state-of-the-art literature review" International journal of management reviews., vol. 9, no. 1, pp. 53-80, 2007.

18. C. Gimenez, V. Sierra and J. Rodon, "Sustainable operations: Their impact on the triple bottom line" International Journal of Production Economics., vol. 140, no. 1, pp. 149-159, 2012.

19. A. Bon, A. Zaid and A. Jaaron, "Green human resource management, Green supply chain management practices and Sustainable performance" in 8th International Conference on Industrial Engineering and Operations Management, pp. 167-176, 2018.

20. C. Yang, C. Lu, J. Haider and P. Marlow, "The effect of green supply chain management on green performance and firm competitiveness in the context of container shipping in Taiwan." Transportation Research Part E: Logistics and Transportation Review., vol. 55, pp. 55-73, 2013

21. Q. Zhu, J. Sarkis and K. Lai, "Examining the effects of green supply chain management practices and their mediations on performance improvements." International journal of production research., vol. 50, no. 5, pp. 1377-1394, 2012.

22. Q. Zhu, J. Sarkis, J. Cordeiro and K. H. Lai, "Firm-level correlates of emergent green supply chain management practices in the Chinese context.”. Omega, vol. 36, no. 4, pp. 577-591, 2008.

23. J. Paauwe, HRM and performance: Achieving long-term viability, New York: Oxford University Press on Demand, 2004.

24. K.W. Green, P. Zelbst, J. Meacham and V. S. Bhadauria, "Green supply chain management practices: impact on performance", Supply Chain Management: An International Journal., vol. 17, no. 3, pp. 290-305, 2012.

25. A. Diabat, R. Khodaverdi and L. Olfat, "An exploration of green supply chain practices and performances in an automotive industry", The International Journal of Advanced Manufacturing Technology., vol. 68, no. 4, pp. 949-961, 2013.

26. A. de Sousa Jabbour, D. Vazquez-Brust, C. Jabbour and H. Latan, "Green supply chain practices and environmental performance in Brazil: survey, case studies, and implications for B2B”, Industrial Marketing Management., vol. 66, pp. 13-28, 2017.

27. T. Laosirihongthong, D. Adebanjo and K. Choon, "Green supply chain management practices and performance", Industrial Management \& Data Systems., vol. 113, no. 8, pp.1088-1109, 2013.

28. S. Koh, A. Gunasekaran and C. Tseng, "Cross-tier ripple and indirect effects of directives WEEE and RoHS on greening a supply chain", International Journal of Production Economics., vol. 140, no. 1, pp. 305-317, 2012

29. P. Rao and D. Holt, "Do green supply chains lead to competitiveness and economic performance?" International journal of operations \& production management., vol. 25, no. 9, pp. 898-916, 2005.

30. R. Sroufe, "A framework for strategic environmental sourcing” Greening the supply chain, pp. 3-23, 2006.

31. Porter and M. R. Kramer, "Strategy \& Society. The link between competitive advantage and corporate social responsibility". Harvard Business Review., pp. 1-14, 2007.

32. D. Holt and A. Ghobadian, "An empirical study of green supply chain management practices amongst UK manufacturers." Journal of Manufacturing Technology Management., vol. 20, no. 7, pp. 933-956, 2009.

33. C. Carter, R. Kale and C. M. Grimm, "Environmental purchasing and firm performance: an empirical investigation" Transportation Research Part E: Logistics and Transportation Review., vol. 36, no. 3, pp. 219-228, 2000

34. S. Rani and K. Mishra, "Green HRM: Practices and strategic implementation in the organizations." International Journal on Recent and Innovation Trends in Computing and Communication., vol. 2, no. 11, pp. 3633-3639, 2014

35. J. Elkington, The Triple Bottom Line, Does It All Add Up?: Assessing the Sustainability of Business and CSR/John. Elkington: Earthscan Publications Ltd, 2004.

36. T. Eltayeb and S. Zailani, "Greening Supply Chain through Supply Chain Initiatives towards Environmental Sustainability" Internationa Journal Environment Science Technology., vol. 2, no. 5, pp. 506-516, 2011.

37. Y. Dou, Q. Zhu and J. Sarkis, "Evaluating green supplier development programs with a grey-analytical network process-based methodology" European Journal of Operational Research., vol. 233, no. 2, pp. 420-431, 2014. 
38. M. Lee, S. Tae Kim and D. Choi, "Green supply chain management and organizational performance." Industrial Management \& Data Systems., vol. 112, no. 8, pp. 1148-1180, 2012

39. S. Zailani, T.K. Eltayeb, C. Hsu and K. Choon, "The impact of external institutional drivers and internal strategy on environmental performance." International Journal of Operations \& Production Management., vol. 32, no. 6, pp. 721-745, 2012.

40. S. Lee, J. Sung, D. Choi and Y. Noh, "Pressures affecting green supply chain performance" Management Decision., vol. 51, no. 8, pp 1753-1768, 2013

41. T. Chiou, H. Chan, F. Lettice andS. H.Chung, "The influence of greening the suppliers and green innovation on environmental performance and competitive advantage in Taiwan." Transportation Research Part E: Logistics and Transportation Review., vol. 47, no. 6, pp. 822-836, 2011.

42. J. Hair, M. Sarstedt, C. Ringle and S. Gudergan, Advanced Issues in Partial Least Squares Structural Equation Modeling, California: SAGE Publications, 2017.

43. W.W. Chin, B. L. Marcolin and P. R. Newsted, "A partial least squares latent variable modeling approach for measuring interaction effects: Results from a Monte Carlo simulation study and an electronic-mail emotion/adoption study.” Information systems research., vol. 14, no. 2 , pp. 189-217, 2013.

44. D. W. Gerbing and J. C. Anderson, "An updated paradigm for scale development incorporating unidimensionality and its assessment.' Journal of marketing research., vol. 25, no. 2, pp. 186-192, 1998.

45. Q. Zhu, J. Sarkis and K. Lai, "Confirmation of a measurement model for green supply chain management practices implementation" International journal of production economics., vol. 111, no. 2, 261-273, 2008 .

46. M. A. Ketokivi and R. G. Schroeder RG, "Perceptual measures of performance: fact or fiction." Journal of Operations Management., vol. 22, no. 3, pp. 247-264, 2004.

47. D. Peng and F. Lai, "Using partial least squares in operations management research: A practical guideline and summary of past research" Journal of Operations Management, vol. 30, no. 6, 467-480, 2012.

48. I. Bernstein and J. Nunnally, Psychometric theory, New York: McGraw-Hill, 1994

49. C. Fornell and D. F. Larcker, "Evaluating structural equation models with unobservable variables and measurement error." Journal of marketing research., vol. 18 , no. 1, pp. 39-50, 1981.

50. J. Henseler, C. M. Ringle and M. Sarstedt, "A new criterion for assessing discriminant validity in variance-based structural equation modelling." Journal of the academy of marketing science., vol. 43, no. 1, pp. $115-135,2015$

51. S. Geisser, "The predictive sample reuse method with applications" Journal of the American statistical Association., vol. 70, no. 350, pp 320-328, 1975.

52. M. Stone, "Cross-validatory choice and assessment of statistical predictions." Journal of the Royal Statistical Society: Series B (Methodological), vol. 36, no. 3, pp. 111-147, 1974

53. J. Cohen, Statistical power analysis for the behavioral sciences, New Jersey: Hilsdale. Lawrence Earlbaum Associates, 1988.

54. T. A. Chin, H. Tat, Z. Sulaiman, M. Zainon and S. N. Liana, "Green Supply Chain Management Practices and Sustainability Performance" Advance Science Letters, vol. 21, no. 5, pp. 1359-1362, 2015.

55. M. Hilton, "SME support for sustainable development: principles and practice," in European Foundation for the Improvement of Living and Working Conditions, Sustainable Development, SMEs and New Enterprises, Office for Official Publications of the European Communities, 2000 .

56. X. Huang, B. L. Tan and X. Ding, "Green supply chain management practices: An investigation of manufacturing SMEs in China' International Journal of Technology Management \& Sustainable Development., vol. 11, no. 2, pp. 139-153, 2012.

57. A. Jabbour, C. Jabbour, D. Vasquez and H. Latan, "The relationship between external GSCM and environmental performance in the light of ecological modernization and resource dependency theory", presented at the British Academy of Management, University of Portsmouth, 2015.

58. C. J. Jabbour, A. Neto, J. Gobbo, M. de Souza Ribeiro and A. de Sousa Jabbour, "Eco-innovations in more sustainable supply chains for a low-carbon economy: A multiple case study of human critical success factors in Brazilian leading companies" International Journal of Production Economics., vol. 164, pp. 245-257, 2015.

59. A. Longoni, D. Luzzini and M. Guerci M, "Deploying Environmental Management Across Functions: The Relationship Between Green Human Resource Management and Green Supply Chain Management' Journal of Business Ethics., vol. 151, no. 4, pp. 1-15, 2016.

60. T. Hahn, F. Figge, J Pinkse and L. Preuss, "Trade-offs in corporate sustainability: you can't have your cake and eat it." Business Strategy and the Environment., vol. 19, no. 4, pp. 217-229, 2010.

61. K. Kitazawa and J. Sarkis, "The relationship between ISO 14001 and continuous source reduction programs." Journal of Operations \& Production Management., vol. 20, no. 2, pp. 225-248, 2000.

62. C. Yang, S. Lin, Y. Chan and C. Sheu C, "Mediated effect of environmental management on manufacturing competitiveness: an empirical study.” International Journal of Production Economics., vol. 123 , no. 1, pp. 210-220, 2010.

63. R. Abdullah, Green Supply Chain Management Practices And Sustainable Performance Among Iso 14001 Manufacturing Firms: The Moderating Effect Of Supply Chain Integration, $\mathrm{PhD}$ Thesis, Universiti Sains Malaysia, 2016.

64. V. Ghosal, A. Stephan and J. Weiss, Decentralized Regulation, Environmental Efficiency and Productivity, Royal Institute of Technology, CESIS-Centre of Excellence for Science and Innovation Studies, 2014.

65. R. Suansawat, The influence of supply chain integration and green supply chain management practices on sustainable firm performance in Thai manufacturing industry, Ph.DThesis, University of Hull, 2013.

66. K. Lai, C. W. Wong and T. Cheng, "Ecological modernisation of Chinese export manufacturing via green logistics management and its regional implications," Technological Forecasting and Social Change, vol. 79 no. 4, pp. 766-770, 2012.

67. Q. Zhu, J. Sarkis and K. Lai, "Initiatives and outcomes of green supply chain management implementation by Chinese manufacturers. Journal of environmental management," vol. 85, no. 1, pp. 179-189, 2007.

68. P. Rao and M. Kondo, "A study to explore the link between green purchasing initiatives and business performance," Great Lakes Herald, vol. 4 , no. 2 , pp. 1-20, 2010.

69. J. Tynon, Examining the environmental performance of first tier suppliers in the oil and gas supply chain industry, Ph.DThesis, University of Agder, 2012.

70. M. Tseng, R. Wang, A. S. Chiu, Y. Geng and Y. H. Lin, "Improving performance of green innovation practices under uncertainty," Journal of cleaner production., vol. 40, pp. 71-82, 2013.

71. A. M. Mohamad and R. Thurasamy, "An Exploratory Study of Green Supply Chain Management Practices and Supply Chain Integration among Malaysia Manufacturing Firms," Australian Journal of Basic and Applied Sciences., vol. 9, no. 37, pp. 50-56, 2015.

72. K. Lai, C. Wong and J. Lam, "Sharing environmental management information with supply chain partners and the performance contingencies on environmental munificence," International Journal of Production Economics, vol. 164, pp. 445-453, 2015.

73. Q. Zhu and J. Sarkis, "An inter-sectoral comparison of green supply chain management in China: drivers and practices," Journal of cleaner production., vol. 14, no. 5, pp. 472-486, 2006.

74. M. Epstein andA. Buhovac, Making sustainability work: Best practices in managing and measuring corporate social, environmental, and economic impacts, Oakland: Berrett-Koehler Publishers, 2014.

75. M. K. Chien,"Influences of green supply chain management practices on organizational sustainable performance" International Journal of Environmental Monitoring and Protection., vol. 1, no. 1, pp. 12-23, 2014.

76. G. Ann, S. Zailani and N. Abd Wahid, "A study on the impact of environmental management system (EMS) certification towards firms performance in Malaysia" Management of Environmental Quality: An International Journal., vol. 17, no. 1, pp. 73-93, 2006.

77. Q. Zhu, Y. Geng and K. Lai, "Circular economy practices among Chinese manufacturers varying in environmental-oriented supply chain cooperation and the performance implications," Journal of Environmental Management., vol. 91, no. 6, pp. 1324-1331, 2010

78. S. Vachon and R. D. Klassen, "Environmental management and manufacturing performance: The role of collaboration in the supply chain" International journal of production economics., vol. 111, no. 2 , pp. 299-315, 2008 .

79. G. Keoleian and D. Menerey, "Life cycle design guidance manual: Environmental requirements and the product system," in Life cycle design guidance manual: environmental requirements and the product system, 2013.

80. C. Wong, S. Boon and C. W. Wong, "The contingency effects of environmental uncertainty on the relationship between supply chain integration and operational performance," Journal of Operations management., vol. 29, no. 6, pp. 604-615, 2011.

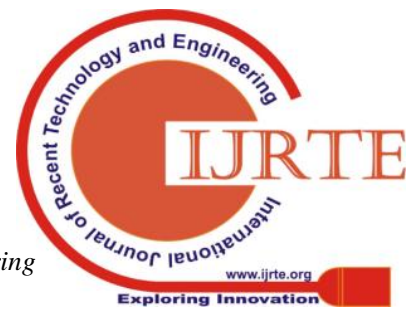

